\section{Shielding the Electromagnetic Waves by Inserting Conductive Lightweight Materials into Woven Curtains}

\section{Izabela Ciesielska Wróbel ${ }^{1 *}$, Jos Knockaert ${ }^{2}$, Gilbert De Mey ${ }^{3}$ and Lieva Van Langenhove ${ }^{1}$}

\begin{abstract}
This preliminary study presents screening curtains made of electro-conductive yarns introduced into woven structures, which provide similar screening abilities as those offered by commercially available metallic plates. The curtains have a major advantage of being flexible so that they are easier to install and to remove. In order to provide a lightweight solution to compare the existing solutions present at the market, one proposes using (1) a carbon yarn (200 tex) and (2) a nickel-coated carbon yarn (1420 tex) as wefts in the woven structures responsible for conducting. The fabrics were separately tested in the electromagnetic compatibility (EMC) anechoic room, which is non-reflective and echo-free laboratory chamber. Transmitting and receiving antennas were installed inside of this chamber. The antennas configuration was also changed to observe the influence of these devices set-up on the screening abilities of the curtains. The preliminary results indicated that in the frequency of $628 \mathrm{MHz}$, the screening ability of the fabric made of (2) was $57.77 \mathrm{~dB}$.
\end{abstract}

Keywords:

Shielding ability of fabrics; Conductive fabrics; Electromagnetic waves; Protection against electromagnetic waves

\section{Introduction}

There are many sources of the electromagnetic radiation (EMR) present in the closest environment of humans and some of them may be dangerous to their health. One often uses the phrase "electromagnetic pollution" to characterize the phenomenon of the presence of this EMR [1-3]. Shielding electromagnetic waves can be easily executed by metallic plates placed in the area where such pollution exists. However, this solution is not practical as the plates are heavy and not flexible. Unlike naturally existing EMR, the presence of the one, which is artificial, is increasing and it has a negative impact of living organisms [1]. It is difficult to identify clearly and characterize all the potential risks coming from the fact of being exposed to EMR and also quantify all the exposure factors, e.g. frequency, time, body zone $[1,2,4]$. One of the most important steps, which were taken to protect

*Corresponding author: Izabela Ciesielska Wróbel, Centre for Textile Science and Engineering, Department of Materials, Textiles and Chemical Engineering, Ghent University, Belgium, Tel: + 092645830; Fax: 092645832;

E-mail: Izabela.CiesielskaWrobel@UGent.be

Received: November 24, 2017 Accepted: January 11, 2018 Published: January 16, 2018 humans from EMR was screening the areas which were occupied by them. Depending on the requirements different materials are utilized to screen the EMR and these materials are applied in different configurations. Among commercially available solutions for shielding of EMR one may find knitted [5,6] and woven structures [7] as well as non-wovens and nets. In terms of raw materials for screening, one utilizes the electrical conductors and ferromagnetic materials and their compounds, e.g. copper, iron, nickel, steel, aluminum, gold, silver and cobalt, iron, copper and manganese. Not all of the mentioned materials are easily applicable into thread textiles - like products and therefore into fabric structures due to their stiffness and fragility when in the form of thread-like item. As a consequence, different types of raw materials and a different manner of their application into the screening materials offer different ranges of screening abilities.

The purpose of the study was to determine if the carbon yarn, with and without the coating, being a conductor may provide with a protection against EMR when introduced into woven structure as a weft.

\section{Materials and Methods}

In order to provide a lightweight solution to compare the existing solutions present at the market, one proposes using (1) a carbon yarn (200 tex) and (2) a nickel-coated carbon yarn (1420 tex) as wefts in the woven structures responsible for conducting. Thus, the first fabric in the current study was made up of polyester warp yarn (16.7 tex) and (1) carbon weft yarn. The second fabric was made of the same warp as in case of the first fabric and (2) nickel-coated carbon weft yarn. Both fabrics have a plain weave. Due to the possibility of electrical discharges generation while weaving process, the fabrics were made in the experimental facility of Picanol, Belgium.

Figures 1 and 2 present woven structures with the carbon weft and with the nickel-coated carbon weft, respectively.

Both images were taken by OneBird Smart 5M 300X USB Digital Microscope Camera Video With MicroCapture.

The characteristics of both fabrics were presented in Table 1.

HTA40 is a classic Tenax ${ }^{\otimes}$ high performance carbon fiber. The high tenacity (HT) fibers provide excellent mechanical laminate properties.

HTS40 is a family of high strength/standard modulus aerospace grade carbon fibers produced in Japan (J) and Europe (E) for use as reinforcement in high performance composites. These fibers are produced from poly-acrylonitrile (PAN) precursor and are surface treated to promote adhesion to organic matrix polymers.

\section{Testing Set-up}

The tests of the screens were performed in an anechoic room, which is non-reflective and echo-free laboratory chamber of Ghent University in Kortrijk Campus. The test was divided into four parts and in each part the set-up of the antennas (signal transmitter and signal receiver) was different (vertical or horizontal) to observe how 


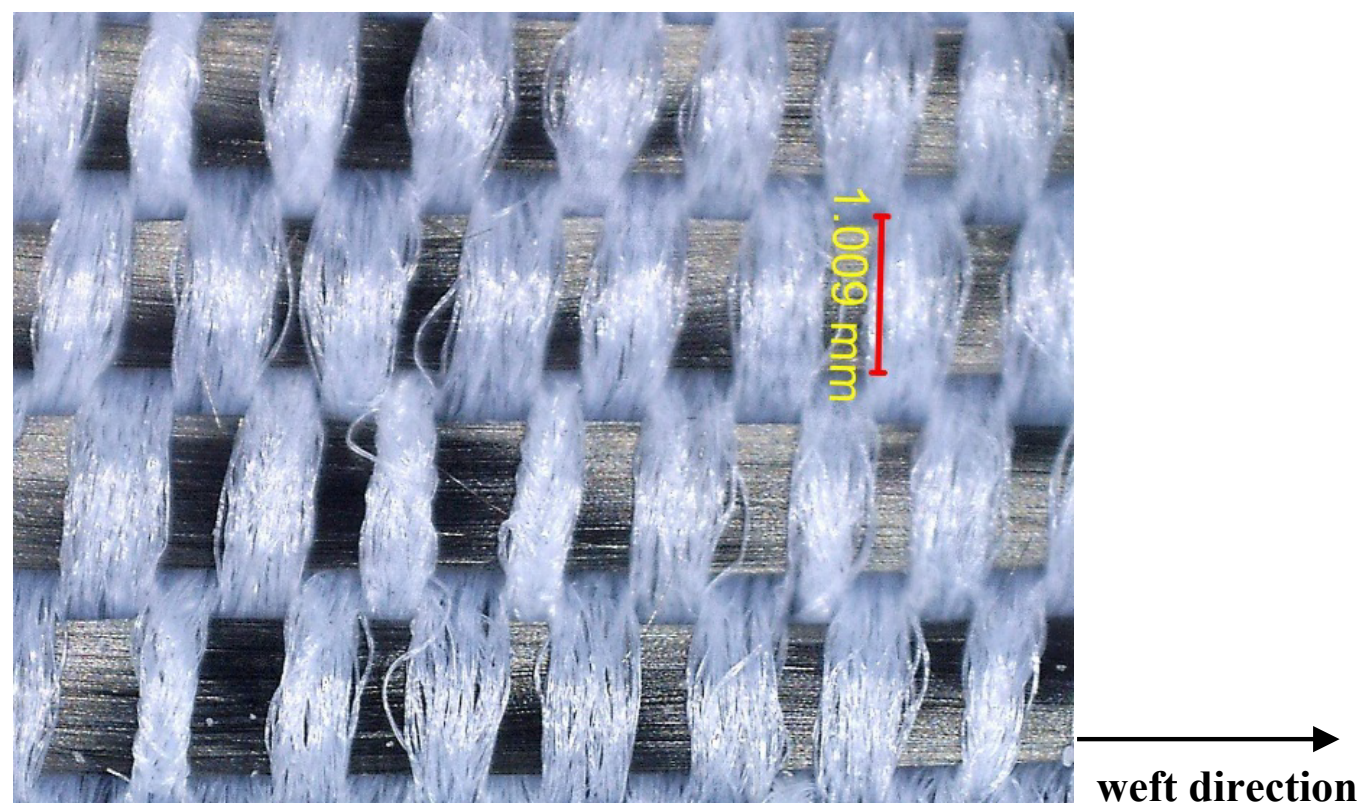

Figure 1: The view on a single layer of a woven structure made of polyester warps and carbon wefts.

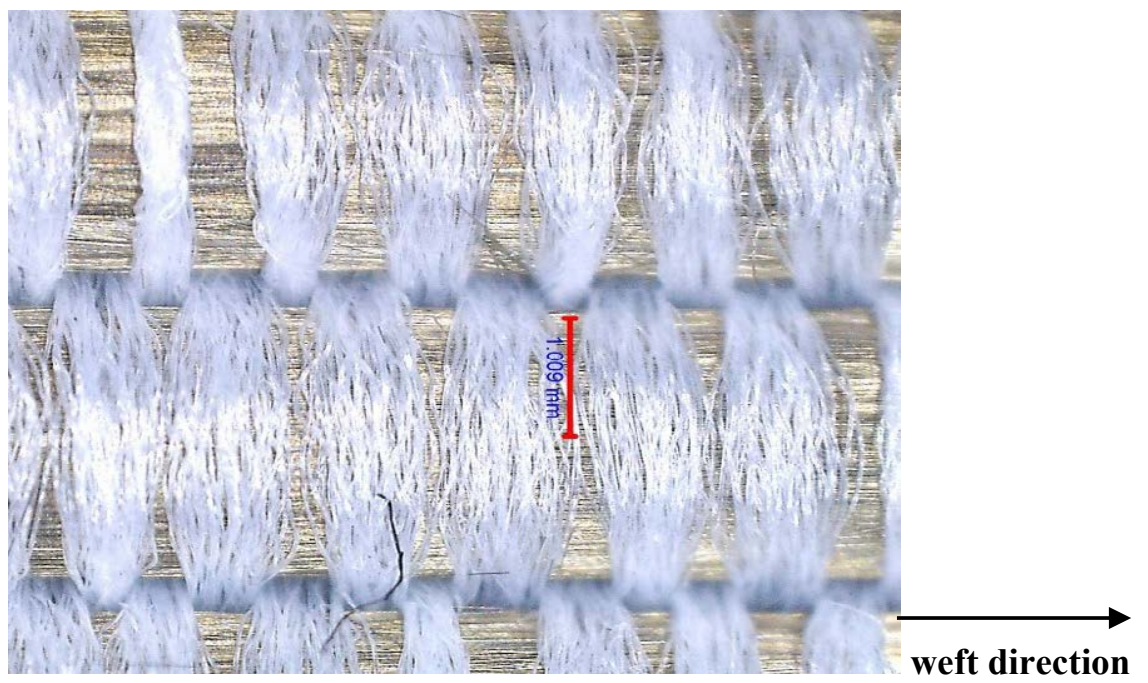

Figure 2: The view on a single layer of a woven structure made of of polyester warps and nickel - coated carbon wefts.

this change of antennas configuration influences the overall ability of the fabrics to screen the transmitted signal between antennas. As Figure $3 \mathrm{a}$ and $3 \mathrm{~b}$ present, the first antenna was placed in a metal cabinet having one of the walls filled by a tested screen. The second antenna is partially visible in Figure $3 \mathrm{~b}$ and fully visible in Figure $3 \mathrm{c}$.

The four set-ups of antennas were as follows:

antenna inside in vertical position $(\mathrm{V})$, antenna outside in vertical position $(\mathrm{V})$;

antenna inside $\mathrm{V}$, antenna outside $\mathrm{H}$;

antenna inside $\mathrm{H}$, antenna outside $\mathrm{H}$;

antenna inside $\mathrm{H}$, antenna outside $\mathrm{V}$.
The range of the signals applied for tests in the characterized experiments was starting from $0 \mathrm{~Hz}$ through extremely low frequencies $(\mathrm{Hz})$ up to ultra-high frequencies $(\mathrm{GHz})$, which in case of this test was $1 \mathrm{GHz}$.

\section{Results}

The results indicated that the fabric containing nickel-coated carbon wefts presented better shielding efficiency of the antenna signals than the fabric containing carbon wefts. Figure 4 presents the changes in shielding efficiency of this screen in the range of frequency from 0 up to $1 \mathrm{GHz}$ and Figure 5 presents changes in shielding efficiency of the same screen in the same range of frequencies versus a reference test (Table 2). 
Citation: Wróbel IC, Knockaert J, De Mey G, Langenhove LV (2018) Shielding the Electromagnetic Waves by Inserting Conductive Lightweight Materials into Woven Curtains. J Fashion Technol Textile Eng S4:001.

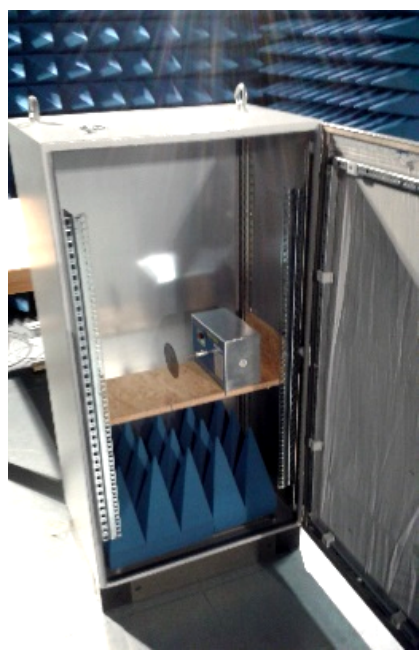

(a)

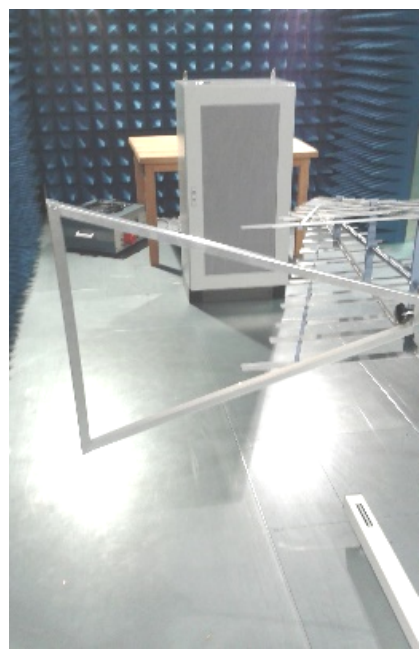

(b)

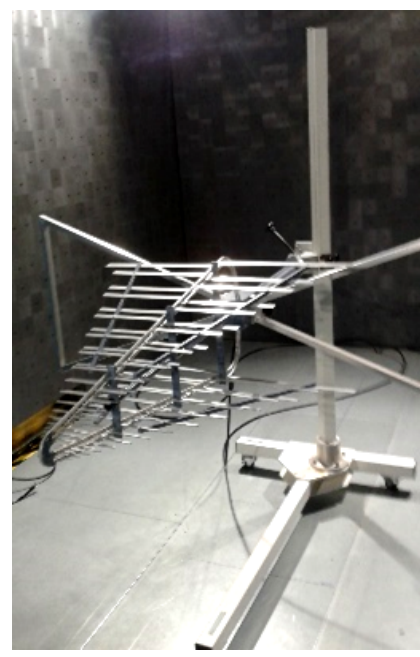

(c)

Figure 3: The interior of the anechoic room, which is non-reflective and echo-free laboratory chamber. The walls of the chamber are covered in Carbon-Based Foam Microwave Absorbers (blue color cones) on one side of the chamber and Ferrite Tile Absorbers on the other side; (a) a metal cabinet with one wall (door) filled in with a tested material. One of the antennas is placed in the cabinet; (b) a view on the closed cabinet; (c) a view on a secon antenna.

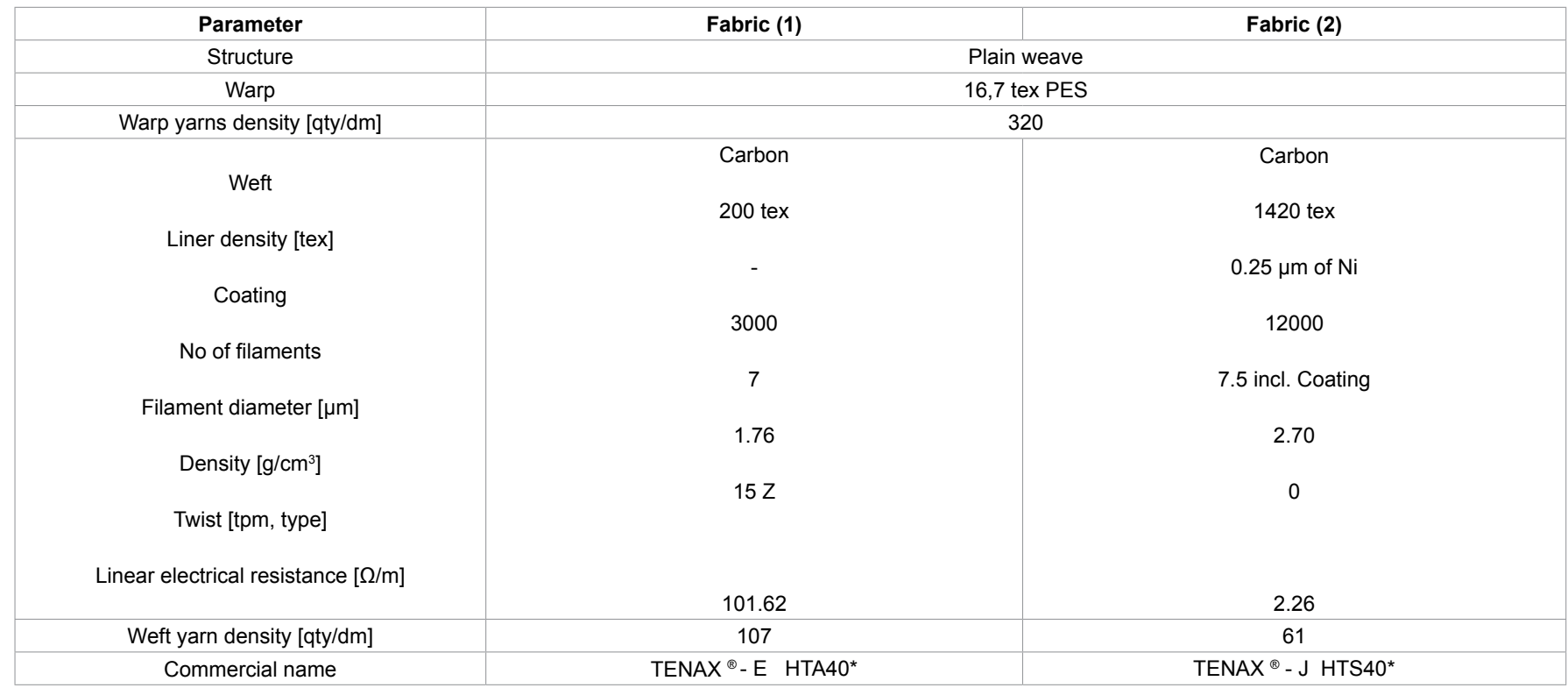

*the provider of the yarns is Toho Tenax Europe $\mathrm{GmbH}$, Germany and the producer of the yarns is Teijin, Japan.

Table 1: Characteristics of yarns and woven structures - screens.

\begin{tabular}{|c|c|c|c|c|c|c|}
\hline \multirow[b]{2}{*}{ Test set-up } & \multicolumn{2}{|c|}{ Fabric (1): Carbon } & \multicolumn{2}{|c|}{ Fabric (2): Carbon + Nickel } & \multicolumn{2}{|c|}{ No fabric } \\
\hline & $\begin{array}{c}\text { Shielding efficiency } \\
{[\mathrm{dB}]}\end{array}$ & Frequency [MHz] & $\begin{array}{c}\text { Shielding efficiency } \\
{[\mathrm{dB}]}\end{array}$ & Frequency [MHz] & $\begin{array}{c}\text { Shielding efficiency } \\
{[\mathrm{dB}]}\end{array}$ & Frequency [MHz] \\
\hline $\begin{array}{l}\text { antenna inside } V \\
\text { antenna outside } V\end{array}$ & 80.62 & 30.00 & 53.36 & 538.04 & 73.76 & 32.00 \\
\hline $\begin{array}{l}\text { antenna inside } \mathrm{V} \\
\text { antenna outside } \mathrm{H}\end{array}$ & - & - & 57.77 & 628.08 & - & - \\
\hline $\begin{array}{l}\text { antenna inside } \mathrm{H} \\
\text { antenna outside } \mathrm{H}\end{array}$ & 53.59 & 456.04 & 77.94 & 30.00 & 80.71 & 30.00 \\
\hline $\begin{array}{l}\text { antenna inside } \mathrm{H} \\
\text { antenna outside } \mathrm{V}\end{array}$ & - & - & 50.39 & 224.04 & - & - \\
\hline
\end{tabular}

${ }^{* *}$ so far not all the variants have been tested.

Table 2: The highest achieved values of shielding efficiency [dB] for tested fabrics** 
Citation: Wróbel IC, Knockaert J, De Mey G, Langenhove LV (2018) Shielding the Electromagnetic Waves by Inserting Conductive Lightweight Materials into Woven Curtains. J Fashion Technol Textile Eng S4:001.

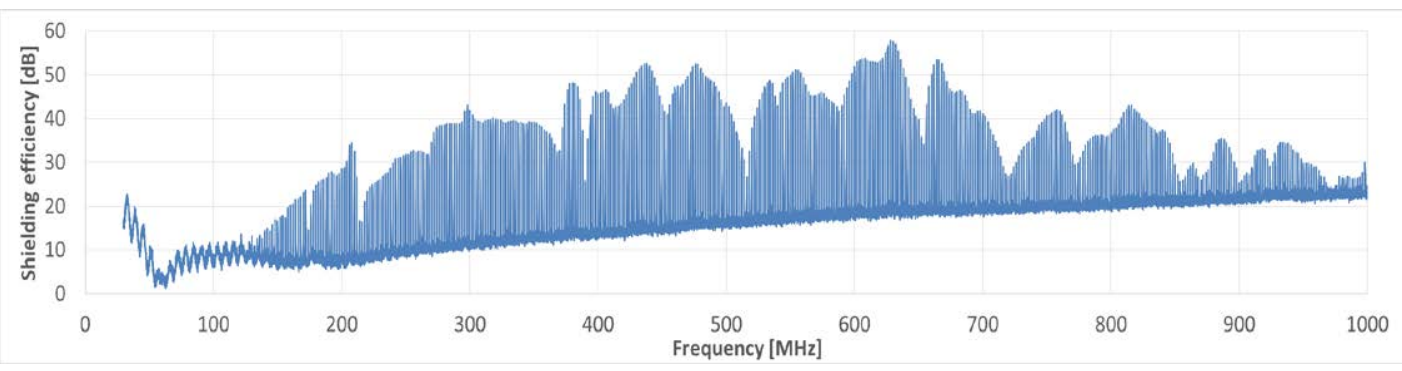

Figure 4: Shielding efficiency of the tested fabric containing wefts made of nickel-coated carbon when the direction of the antennas were $V$ (inside antenna) and $\mathrm{H}$ (outside antenna).

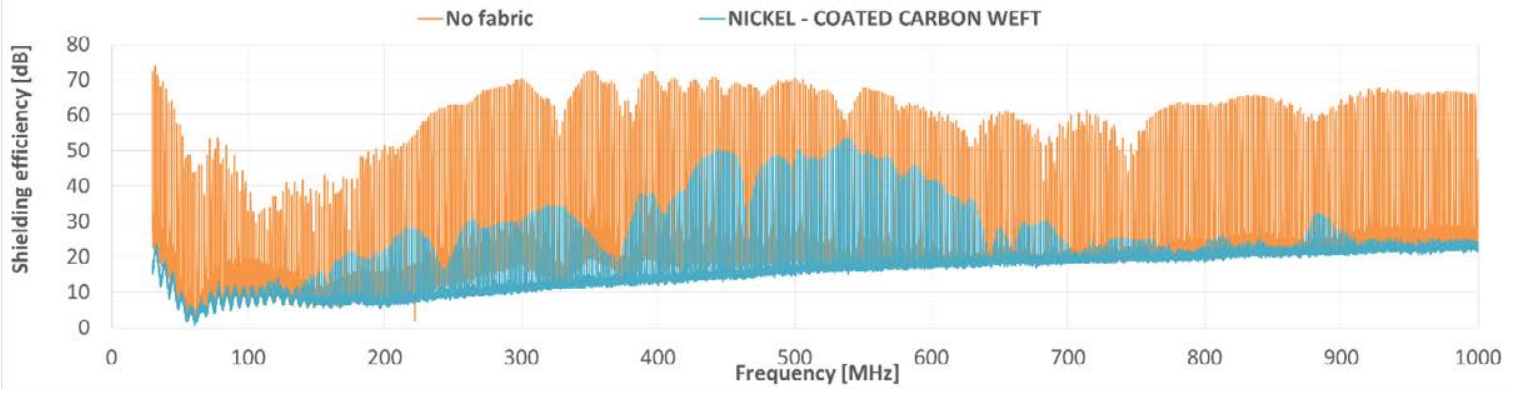

Figure 5: Shielding efficiency of the tested fabric containing wefts made of nickel-coated carbon versus reference test (no fabric) when the direction of the antennas were $\mathrm{V}$ (inside antenna) and $\mathrm{V}$ (outside antenna).

\section{Conclusions}

On the base of the assumption that the conductive yarn introduced into a fabric may greatly support shielding efficiency of EMR one selected two of them to play the role of wefts. The yarn with nickel coating presents higher shielding efficiency in high frequency range of the spectrum. At this stage of the test only one of the set-up of the antennas could be compared. It was expected that increase in the number of layers of the fabrics placed on top of one another at and/ or changing a phase shift angle of one of the layers to compare to the second one can present even higher shielding efficiency.

\section{References}

1. Aniołczyk H (2000) Electromagnetical field: sources, influence, protection Thesis, The Nofer Institute of Occupational Medicine, Lodz, Poland.

2. DG Health and Consumer Protection (2002) European information system on electromagnetic fields exposure and health impacts.

3. EUR-Lex (2004) Directive 2004/40/WE European Parliament from 29th April 2004 concerning the minimal demanding referring the health protection and the security of the employees exposed to the physical hazards (electromagnetical field) art. 16 point 1 of the directive 89/391/EWG), No L-184.
4. Marciniak K, Grabowska K, Stempień Z, Ciesielska-Wróbel I, Rutkowska A, et al. (2016) Woven Fabrics Containing Hybrid Yarn for Shielding Electromagnetic Radiation. Fibres Text East Eur 6: 109-115.

5. Ciesielska-Wróbel I, Grabowska K, Marciniak K (2014) Polish Patent no PL 215706 B1 entitled knitted fabric capable of screening electromagnetic radiation.

6. Ciesielska Wróbel I, Grabowska K (2012) Estimation of the EMR Shielding Effectiveness of Knit Structures. Fibres Text East Eur 2: 53-60.

7. Grabowska K, Marciniak K, Ciesielska Wróbel IL (2011) The analysis of attenuation of electromagnetic field by woven structures based on hybrid fancy yarns. Text Res J 81: 1578-1593.

\section{Author Affiliations}

${ }^{1}$ Centre for Textile Science and Engineering, Department of Materials, Textiles and Chemical Engineering, Ghent University, Belgium

${ }^{2}$ Department of Electrical Energy, Systems and Automation, Campus Kortrijk, Ghent University, Belgium

${ }^{3}$ Department of Electronics and Information Systems, Ghent University, Belgium

Submit your next manuscript and get advantages of SciTechnol submissions
* 80 Journals
* 21 Day rapid review process
* 3000 Editorial team
* 5 Million readers
* More than 5000
* Quality and quick review processing through Editorial Manager System

Submit your next manuscript at • www.scitechnol.com/submission 